\title{
Suicide in Hong Kong: a case-control psychological autopsy study
}

\author{
ERIC Y. H. CHEN*, WINCY S. C. CHAN, PAUL W. C. WONG, SANDRA S. M. CHAN, \\ CECILIA L. W. CHAN, Y. W. LAW, PHILIP S. L. BEH, K. K. CHAN, \\ JOANNE W. Y. CHENG, KA Y. LIU AND PAUL S. F. YIP \\ Hong Kong Jockey Club Centre for Suicide Research and Prevention, University of Hong Kong, \\ Pokfulam, Hong Kong
}

\begin{abstract}
Background. The relative contribution of psychosocial and clinical risk factors to suicide among Chinese populations is an important issue. In Hong Kong, this issue requires vigorous examination in light of a $50 \%$ increase in suicide rate between 1997 and 2003.
\end{abstract}

Method. Using a case-control psychological autopsy method, 150 suicide deceased were compared with 150 living controls matched by age and gender. Semi-structured interviews were conducted with the next-of-kin of the subjects. Data were collected on a wide range of potential risk and protective factors, including demographic, life event, clinical and psychological variables. The relative contribution of these factors towards suicide was examined in a multiple logistic regression model.

Results. Six factors were found to significantly and independently contribute to suicide: unemployment, indebtedness, being single, social support, psychiatric illness, and history of past attempts.

Conclusions. Both psychosocial and clinical factors are important in suicides in Hong Kong. They seem to have mediated suicide risk independently. In addition, socio-economic adversities seem to have played a relatively important role in the increasing suicide rate in Hong Kong.

\section{INTRODUCTION}

The relationship between clinical and psychosocial risk factors of suicide has been an important theme in contemporary suicide research. A recent study in China reported the relative importance of psychosocial factors and suggested the need to further understand how suicide risk factors interact in Chinese populations (Phillips et al. 2002). There have been only a few reported psychological autopsy studies involving Chinese populations. Cheng et al. (2000) reported how psychiatric illnesses

\footnotetext{
* Address for correspondence: Dr Eric Y. H. Chen, Department of Psychiatry and HKJC Centre for Suicide Research and Prevention, 3B, No. 2 University Drive, University of Hong Kong, Pokfulam, Hong Kong.

(Email: eyhchen@hku.hk)
}

might interact with psychosocial risk factors in Han Chinese and two aboriginal groups in East Taiwan. Phillips et al. (2002) found that while only $63 \%$ of the suicide cases in Mainland China had met the criteria of a psychiatric illness, stressful life events were important predictors. The predominantly Chinese population in Hong Kong offers an opportunity to explore the relevance of psychosocial risk factors in a Chinese population experiencing rapid socioeconomic changes.

The socio-economic adversity in Hong Kong in the past few years has been paralleled by a $50 \%$ increase in suicide rate from $12 \cdot 1 / 100000$ in 1997 to $18 \cdot 6 / 100000$ in 2003 (CSRP, 2005). A previous study conducted in 1998 focused mainly on psychiatric morbidity in the Hong 
Kong elderly population (Chiu et al. 2004). We report here a case-control psychological autopsy study that aimed to understand the phenomenon of suicide in the youth and adult populations in Hong Kong between 2002 and 2004 with an emphasis on the relative importance and potential interactions between clinical and psychosocial factors.

\section{METHOD}

This study investigated suicides among those with an ethnic Chinese background and aged 15 to 59 in Hong Kong between 2002 and 2004. Suicide risk and protective factors were investigated by a systematic case-control design. These factors include various sociodemographic factors, life events, and clinical and psychological conditions. The study was approved by the Institutional Review Board of the University of Hong Kong/Hospital Authority Hong Kong West Cluster (HKU/HA HKW IRB) and the Ethics Committee of the Department of Health, Hong Kong SAR.

\section{Participants}

Suicide cases

Cases of suicides were identified from the deaths registered as 'suicide' by the coroner. The suicide cases of this study were limited to people aged 15-59 years who committed suicide between August 2002 and December 2004. Cases for psychological autopsy interviews were recruited by two methods: first through the forensic pathology service and second through the Coroner's Court. A total of 1038 eligible suicide cases were approached through these two pathways. The first 150 informants who gave consent to the study were included.

\section{Control sample}

The sample pool for the control group consisted of 2219 individuals randomly selected from 4.8 million people aged 15-59 years in Hong Kong to participate in another epidemiological study. One hundred and fifty subjects, matched for age and gender with the suicide deceased, were recruited in the present study. The closest relatives of the subjects were invited to participate in the interviews to give information on the same set of questions as in the psychological autopsy interview.

\section{Measures}

\section{Circumstances of death}

We studied the methods, location and date of suicide, the time interval between the suicidal thought and the fatal act, the presence of suicide notes, and communication of suicidal intent. Suicide methods along with the agegender distribution of the sample were compared to those of all suicide cases aged 15-59 years in 2003 to assess representativeness of the sample.

\section{Sociodemographic characteristics}

The demographic characteristics investigated in this study included marital status, educational status, ethnicity, living arrangements, employment status, income and financial situation.

\section{Familial and social support factors}

Familial factors were investigated, including expressed emotions within the family, the presence of extramarital affairs and domestic violence. The level of expressed emotions within families was measured by a modified version of the Level of Expressed Emotions (LEE; Cole \& Kazarian, 1993). Domestic violence was assessed by the Revised Conflict Tactics Scales (CTS-2; Moraes \& Reichenheim, 2002). Social support was evaluated by three aspects: size of social support network, frequency of social activities within the past month, and social support content. First, the size of social support was indicated by the number of close family members, extensive relatives and friends whom the subjects were able to rely on when encountering life problems. Second, frequency of social activities of the subjects in the past month was recorded. Third, four features of social support, including emotional, instrumental, informational and appraisal support, were assessed by scenario-based questions and quantified to evaluate the accessibility of support within a social network.

\section{Life event variables}

Life events in the past year were identified and their negative impacts on the subjects were evaluated. In addition, acute life events referred to those events that happened within a month of 
the death. A checklist consisting of 43 culturally specific negative events was constructed to evaluate five life situations: relationship, family, work and school, physical health, and legal issues. The overall psychological impact of the five life-situations was quantified as in the study by Phillips et al. (2002).

\section{Clinical factors}

Psychiatric illness was investigated using a locally validated version of the Structured Clinical Interview for DSM-IV-TR Axis-I Disorders (SCID-I) to best estimate DSM-IV-TR diagnoses (APA, 2000) of Axis-I psychiatric disorders. This version of the SCID-I was reported to be reliable in measuring bipolar disorders $(\kappa=0 \cdot 84)$, major depressive disorders $(\kappa=0.76)$, schizophrenia $(\kappa=0.75)$, alcohol and substance use disorders $(\kappa=0.93)$, anxiety disorders $(\kappa=0.81)$ and adjustment disorders $(\kappa=0.64)$ in psychiatric patients (So et al. $2003 a, b)$. We also included two additional Axis-I disorders, namely pathological gambling and intermittent explosive disorder, to investigate culturally specific impulsive control disorders. The final diagnoses were made at consensus meetings within the research team after the interviews. History of physical illness, past suicidal behaviours and family history of suicide were recorded.

\section{Psychological features}

Psychological factors measured included impulsivity, compulsive buying, social problem solving and healthy living styles. Impulsive-state behaviour was measured by the Impulsivity Rating Scale (IRS; Lecrubier et al. 1995). Compulsive buying was screened by a sevenitem instrument (Faber \& O'Guinn, 1992). Social problem solving was assessed by a shortened eight-item Social Problem-Solving Inventory (SPSI; D'Zurilla \& Nezu, 1990) to measure four constructs (problem orientation, generation of alternative solutions, decision making, and solution implementation and solution verification) of social problem-solving abilities. A culturally specific scale on healthy living styles was developed to measure five aspects of healthy living: healthy diet, physical activities, emotional expressions, interests and habits, and continual learning.

\section{Data collection}

Interview procedures

The next-of-kin of the suicide deceased were invited to an interview following the incident usually after no less than 6 weeks to allow bereavement and after no more than 12 months to avoid recall limitations. The psychological autopsy interviews of the 150 cases were carried out at an average of $7 \cdot 3$ (S.D. $=4 \cdot 0)$ months after the death incident. During the interview, a semistructured interview schedule was administered by trained interviewers.

\section{Consensus meeting}

Detailed case discussions took place to ensure the validity of information and to provide optimal interpretation of potentially ambiguous information. These discussions were led by psychiatrists (E.Y.H.C. and S.S.M.C.) of the research team. A strategy was developed to systematically handle discrepant information from different sources. In particular, symptoms of psychiatric illnesses were discussed in detail and consensus diagnoses were reached.

\section{Statistical analyses}

We used SPSS-PC software version 12.0 (SPSS Inc., Chicago, IL, USA) for statistical analyses. We first compared the age and gender distributions and the method of suicide between our suicide sample $(n=150)$ and all suicide victims aged $15-59$ in $2003(n=879)$ to assess the representativeness of the sample. We then compared our suicide sample with the matched control group. We compared the samples with respect to sociodemographic variables, impacts of negative life events, and clinical and psychological factors. Binary logistic regression models were used to obtain the unadjusted odds ratios (ORs) and their 95\% confidence intervals (CIs) for each independent variable. Significant variables were then entered into a multivariate logistic regression model. A stepwise elimination method was used to identify a stable model. Multi-collinearity of the final model was tested but was found to be insignificant. We also used dummy variables to test interaction effects between mental illness (mood and substance use disorders) and significant life event variables (relationship, work and school, physical health, acute relationship problems). 
Table 1. Age and gender distributions in the sample and all suicides aged 15-59 years in Hong Kong, 2003 (\%)

\begin{tabular}{|c|c|c|c|c|}
\hline \multirow{2}{*}{$\begin{array}{l}\text { Age } \\
(\mathrm{yr})\end{array}$} & \multicolumn{2}{|c|}{ Sample $(n=150)$} & \multicolumn{2}{|c|}{$\begin{array}{l}\text { All suicide victims aged } \\
15-59 \text { years, } 2003(n=879)\end{array}$} \\
\hline & Women & Men & Women & Men \\
\hline $15-24$ & $6 \cdot 0$ & $8 \cdot 0$ & $4 \cdot 3$ & $6 \cdot 4$ \\
\hline $25-34$ & $8 \cdot 7$ & $13 \cdot 3$ & $9 \cdot 7$ & $14 \cdot 4$ \\
\hline $35-44$ & $8 \cdot 0$ & $20 \cdot 7$ & $8 \cdot 0$ & $20 \cdot 5$ \\
\hline $45-54$ & $10 \cdot 7$ & $14 \cdot 7$ & $7 \cdot 3$ & $18 \cdot 9$ \\
\hline$>54$ & $2 \cdot 7$ & $7 \cdot 3$ & $3 \cdot 4$ & $7 \cdot 2$ \\
\hline Total & $36 \cdot 0$ & $64 \cdot 0$ & $32 \cdot 7$ & $67 \cdot 3$ \\
\hline
\end{tabular}

a Data from the Coroner's Court, Hong Kong Special Administrative Region.

\section{RESULTS}

\section{Age and gender distributions of suicide deceased}

Of the 150 suicide cases studied, 96 were males and 54 were females. The age and gender distributions are reported in Table 1 . The mean age of the sample was 38.7 (s.D. $=11.3$ ) years, while that of the males was $39 \cdot 4$ (s.D. $=11 \cdot 2$ ) and that of the females was $37 \cdot 5$ (s.D. $=11 \cdot 6)$. There was no significant difference in the age distributions between the sample and all suicides aged 15-59 years in 2003, either in males $(p=0.54)$ or in females $(p=0.69)$. The male to female ratio in the sample was $1.78: 1$, whereas that in all suicide victims was $1.92: 1$.

\section{Circumstances of death}

Of the 150 cases, $72(48 \cdot 0 \%)$ died by jumping from a height, $50(33 \cdot 3 \%)$ by charcoal burning, $19(12.7 \%)$ by hanging, two $(1.3 \%)$ by drug overdose, and seven $(4.7 \%)$ by other methods (wrist slashing, drowning, jumping in front of a train, ingesting insecticide, poison by domestic gas, stabbing, suffocation). Fourteen (9.3\%) of the cases used multiple means to kill themselves. Comparing the three most common methods used in our sample and in all suicides aged 15-59 in 2003, we found no significant difference in the distribution on jumping $(p=0.71)$, charcoal burning $(p=0.47)$ and hanging $(p=0 \cdot 67)$.

The majority $(119,79 \cdot 3 \%)$ of the deceased died at home. Sixty-five $(43 \cdot 3 \%)$ out of 150 cases left at least one suicide note in the form of a message, letter or diary, and $76(50.7 \%)$ of them either implicitly or explicitly expressed their suicidal plan. According to the informants, $24(16.0 \%)$ of the deceased died within 24 hours of their identifiable suicidal thoughts, $21(14.0 \%)$ from 1 to 7 days, $15(10.0 \%)$ within a week and a month, $17(11.3 \%)$ from 1 to 2 months, and $35(23 \cdot 3 \%)$ had suicidal thoughts for 2 months or more before the act. The informants of 38 cases were unable to provide this information.

\section{Risk and protective factors of suicide}

Table 2 shows the differences between the suicide and control groups on various sociodemographic factors, impact on negative life events, and clinical and psychological conditions. Table 3 shows the distribution of unemployment across age and gender. For male suicide, the impact of unemployment was apparent across different age groups (we noted that unemployment was present in six out of seven suicides aged between 20 and 24 years). By contrast, among the female deceased, unemployment seemed to impact greater in the older age group (i.e. $45-59$ years; $p<0.05$ ).

We also found the suicide deceased were more likely to have suffered from unmanageable financial debts as compared to the community controls. However, we did not identify significant differences across age groups in both genders among the suicide cases (Table 3). We further explored the relationship between indebtedness and suicide by excluding those individuals who were pathological gamblers and compulsive buyers, and found that the relationship was still highly significant (OR $6 \cdot 38,95 \%$ CI $2 \cdot 37-17 \cdot 22, p<0 \cdot 001)$.

Furthermore, the suicide deceased had also experienced physical abuse at home (either as the recipient or the perpetrator), received less income, lived alone, had never married, had experienced negative expressed emotions at home, and had a lower education attainment level, compared to the community subjects. By contrast, a wide social network and accessible support were more prevalent in the control group (Table 2).

The suicide cases had also experienced more intensive negative impacts on some life events. Life stressors from relationship, work and school, and physical health in the past year were associated with increased risk of suicide (OR 
Table 2. Unadjusted parameter estimates ${ }^{\mathrm{a}}$ of sociodemographic, life event, and clinical and psychological factors of suicide

\begin{tabular}{|c|c|}
\hline & Odds ratio $(95 \% \mathrm{CI})^{\mathrm{b}}$ \\
\hline \multicolumn{2}{|l|}{$\begin{array}{l}\text { Sociodemographic characteristics } \\
\text { Marital status }{ }^{1}\end{array}$} \\
\hline $\begin{array}{l}\text { Educational level }^{2} \\
\text { Form } 3 \text { or below }\end{array}$ & $1.79(1 \cdot 13-2 \cdot 85)^{*}$ \\
\hline $\begin{array}{l}\text { Birthplace }^{3} \\
\quad \text { Born outside Hong Kong }\end{array}$ & $0.99(0.59-1 \cdot 66)$ \\
\hline $\begin{array}{l}\text { Living arrangement }{ }^{4} \\
\text { Living alone }\end{array}$ & $2 \cdot 92(1 \cdot 81-4 \cdot 71)^{* * *}$ \\
\hline $\begin{array}{l}\text { Employment status }^{5} \\
\text { Unemployed } \\
\text { Economically inactive }\end{array}$ & $\begin{array}{l}9 \cdot 40(4 \cdot 94-17 \cdot 88)^{* * *} \\
1 \cdot 13(0 \cdot 57-2 \cdot 24)\end{array}$ \\
\hline $\begin{array}{l}\text { Monthly income } \\
\text { Below HKD } \$ 7000\end{array}$ & $3 \cdot 57(2 \cdot 18-5 \cdot 82)^{* * *}$ \\
\hline Presence of unmanageable debts & $8.03(3.63-17 \cdot 74)^{* * *}$ \\
\hline $\begin{array}{l}\text { Family relationship } \\
\text { Level of expressed emotions } \\
\text { Extramarital affairs } \\
\text { Psychological abuse }- \text { subject as recipient } \\
\text { Psychological abuse }- \text { subject as perpetrator } \\
\text { Physical abuse }- \text { subject as recipient }{ }^{7} \\
\text { Physical abuse }- \text { subject as perpetrator }\end{array}$ & $\begin{array}{l}1.92(1.45-2 \cdot 56)^{* * *} \\
2 \cdot 23(0 \cdot 60-8 \cdot 21) \\
0.98(0 \cdot 59-1 \cdot 62) \\
1 \cdot 14(0 \cdot 68-1 \cdot 90) \\
4 \cdot 22(1 \cdot 79-9 \cdot 96)^{* *} \\
4 \cdot 12(1 \cdot 73-9 \cdot 77)^{* *}\end{array}$ \\
\hline $\begin{array}{l}\text { Interpersonal relationships } \\
\text { Size of social support network } \\
\text { Frequency of social support } \\
\text { Social support content }\end{array}$ & $\begin{array}{l}0.09(0.02-0.44)^{* *} \\
0.80(0.62-1.03) \\
0.32(0.21-0.47)^{* * *}\end{array}$ \\
\hline $\begin{array}{l}\text { Life event variables } \\
\text { Severity of negative life events } \\
\text { Relationship } \\
\text { Family } \\
\text { Work and school } \\
\text { Physical health } \\
\text { Legal issues }\end{array}$ & $\begin{array}{l}1.33(1.00-1.77)^{*} \\
1.08(0.89-1.31) \\
1.28(1.02-1.61)^{*} \\
1.32(1.02-1.71)^{*} \\
4.78(0.39-58.75)\end{array}$ \\
\hline $\begin{array}{l}\text { Severity of acute negative life events } \\
\text { Relationship } \\
\text { Family } \\
\text { Work and school } \\
\text { Physical health }\end{array}$ & $\begin{array}{l}2 \cdot 50(1 \cdot 02-6 \cdot 13)^{*} \\
0 \cdot 86(0 \cdot 68-1 \cdot 09) \\
0 \cdot 82(0 \cdot 62-1 \cdot 08) \\
1 \cdot 69(0 \cdot 76-3 \cdot 80)\end{array}$ \\
\hline $\begin{array}{l}\text { Clinical factors } \\
\text { At least one psychiatric diagnosis } \\
\text { Ever received some kind of emotional treatment } \\
\text { Ever received psychiatric treatment } \\
\text { Presence of chronic physical illness }^{11} \\
\text { Previous suicidal attempt(s) }{ }^{12} \\
\text { Family history of suicide }^{13}\end{array}$ & $\begin{array}{l}37 \cdot 55(19 \cdot 22-73 \cdot 38)^{* * * *} \\
12 \cdot 21(6 \cdot 10-24 \cdot 43)^{* * * *} \\
21 \cdot 26(8 \cdot 22-54 \cdot 97)^{* * *} \\
3 \cdot 45(1 \cdot 81-6 \cdot 56)^{* * *} \\
59 \cdot 38(14 \cdot 17-248 \cdot 86)^{* * *} \\
1.33(0 \cdot 76-2 \cdot 32)\end{array}$ \\
\hline $\begin{array}{l}\text { Psychological factors } \\
\text { Impulsivity } \\
\text { Compulsive buying }{ }^{14} \\
\text { Social problem-solving skills } \\
\text { Healthy living styles }\end{array}$ & $\begin{array}{l}5 \cdot 45(3 \cdot 22-9 \cdot 21)^{* * *} \\
3 \cdot 79(1 \cdot 73-8 \cdot 31)^{* *} \\
0 \cdot 46(0 \cdot 35-0 \cdot 61)^{* * *} \\
0 \cdot 49(0 \cdot 38-0 \cdot 64)^{* * *}\end{array}$ \\
\hline
\end{tabular}

CI, Confidence interval.

a The parameter estimates for each sociodemographic condition, negative life event, or clinical or psychological condition were controlled by age and gender.

b Reference categories: ${ }^{1}$ currently married or cohabited, ${ }^{2}$ above Form $3,{ }^{3}$ born in Hong Kong, ${ }^{4}$ living with others, ${ }^{5}$ currently employed, ${ }^{6}$ HKD $\$ 7000$ (USD\$900) or more, ${ }^{7}$ no evidence of such abuse, ${ }^{8}$ no psychiatric diagnosis, ${ }^{9}$ never received emotional treatment, ${ }^{10}$ never received psychiatric treatment, ${ }^{11}$ no chronic physical illness, ${ }^{12}$ no previous suicidal attempt, ${ }^{13}$ no family history of suicide, and 14 not a compulsive buyer.

c Life events that occurred in the past year.

d Acute life events that occurred in the past month.

$* * * \quad p<0 \cdot 001, * * p<0 \cdot 01, * p<0 \cdot 05$. 
Table 3. Prevalence of socio-economic and clinical factors in the sample by age and gender

\begin{tabular}{|c|c|c|c|c|c|c|c|c|c|c|c|c|}
\hline \multirow[b]{2}{*}{ Sex } & \multirow[b]{2}{*}{$\begin{array}{l}\text { Age } \\
(\mathrm{yr})\end{array}$} & \multirow[b]{2}{*}{$n$} & \multicolumn{2}{|c|}{ Unemployment } & \multicolumn{2}{|c|}{ Indebtedness } & \multicolumn{2}{|c|}{ Substance abuse } & \multicolumn{2}{|c|}{ Mood disorders } & \multicolumn{2}{|c|}{ Physical illness } \\
\hline & & & $\begin{array}{c}\text { Case } \\
(\%)\end{array}$ & $\begin{array}{c}\text { Control } \\
(\%)\end{array}$ & $\begin{array}{c}\text { Case } \\
(\%)\end{array}$ & $\begin{array}{c}\text { Control } \\
(\%)\end{array}$ & $\begin{array}{c}\text { Case } \\
(\%)\end{array}$ & $\begin{array}{c}\text { Control } \\
(\%)\end{array}$ & $\begin{array}{c}\text { Case } \\
(\%)\end{array}$ & $\begin{array}{c}\text { Control } \\
(\%)\end{array}$ & $\begin{array}{l}\text { Case } \\
(\%)\end{array}$ & $\begin{array}{c}\text { Control } \\
(\%)\end{array}$ \\
\hline \multirow[t]{7}{*}{ M } & $15-19$ & 5 & $1(20 \cdot 0)$ & $0(0 \cdot 0)$ & $1(20 \cdot 0)$ & $0(0 \cdot 0)$ & $1(0 \cdot 2)$ & $0(0 \cdot 0)$ & $2(0 \cdot 4)$ & $0(0 \cdot 0)$ & $0(0 \cdot 0)$ & $0(0 \cdot 0)$ \\
\hline & $20-24$ & 7 & $6(85 \cdot 7)$ & $0(0 \cdot 0)$ & $2(28 \cdot 6)$ & $0(0 \cdot 0)$ & $2(0 \cdot 3)$ & $0(0 \cdot 0)$ & $2(0 \cdot 3)$ & $1(0 \cdot 1)$ & $1(0 \cdot 1)$ & $1(0 \cdot 1)$ \\
\hline & $25-34$ & 20 & $11(55 \cdot 0)$ & $3(15 \cdot 0)$ & $7(35 \cdot 0)$ & $0(0 \cdot 0)$ & $3(0 \cdot 2)$ & $0(0 \cdot 0)$ & $6(0 \cdot 3)$ & $0(0 \cdot 0)$ & $5(0 \cdot 3)$ & $0(0 \cdot 0)$ \\
\hline & $35-44$ & 31 & $14(45 \cdot 2)$ & $2(6 \cdot 5)$ & $13(41.9)$ & $5(0 \cdot 2)$ & $1(0 \cdot 3)$ & $0(0 \cdot 0)$ & $17(0 \cdot 5)$ & $4(0 \cdot 1)$ & $10(0 \cdot 3)$ & $2(0 \cdot 1)$ \\
\hline & $45-54$ & 22 & $10(45 \cdot 5)$ & $0(0 \cdot 0)$ & $8(36 \cdot 4)$ & $2(0 \cdot 1)$ & $3(0 \cdot 1)$ & $0(0 \cdot 0)$ & $8(0 \cdot 4)$ & $2(0 \cdot 1)$ & $8(0 \cdot 4)$ & $6(0 \cdot 3)$ \\
\hline & $55-59$ & 11 & $5(45 \cdot 5)$ & $0(0 \cdot 0)$ & $2(18 \cdot 2)$ & $1(0 \cdot 1)$ & $2(0 \cdot 2)$ & $1(0 \cdot 1)$ & $6(0 \cdot 5)$ & $1(0 \cdot 1)$ & $6(0 \cdot 5)$ & $1(0 \cdot 1)$ \\
\hline & Total & 96 & $47(49 \cdot 0)$ & $5(5 \cdot 2)$ & $33(34 \cdot 4)$ & $8(0 \cdot 1)$ & $12(0 \cdot 1)$ & $1(0 \cdot 1)$ & $41(0 \cdot 4)$ & $8(0 \cdot 1)$ & $30(0 \cdot 3)$ & $10(0 \cdot 1)$ \\
\hline \multirow[t]{7}{*}{$\mathrm{F}$} & $15-19$ & 5 & $1(20 \cdot 0)$ & $0(0 \cdot 0)$ & $0(0 \cdot 0)$ & $0(0 \cdot 0)$ & $0(0 \cdot 0)$ & $0(0 \cdot 0)$ & $3(0 \cdot 6)$ & $0(0 \cdot 0)$ & $0(0 \cdot 0)$ & $0(0 \cdot 0)$ \\
\hline & $20-24$ & 4 & $2(50 \cdot 0)$ & $0(0 \cdot 0)$ & $0(0 \cdot 0)$ & $0(0 \cdot 0)$ & $0(0 \cdot 0)$ & $0(0 \cdot 0)$ & $3(0 \cdot 8)$ & $0(0 \cdot 0)$ & $0(0 \cdot 0)$ & $0(0 \cdot 0)$ \\
\hline & $25-34$ & 13 & $7(53 \cdot 8)$ & $2(15 \cdot 4)$ & $3(23 \cdot 1)$ & $0(0 \cdot 0)$ & $1(0 \cdot 1)$ & $0(0 \cdot 0)$ & $6(0 \cdot 5)$ & $0(0 \cdot 0)$ & $1(0 \cdot 1)$ & $0(0 \cdot 0)$ \\
\hline & $35-44$ & 12 & $4(33 \cdot 3)$ & $7(58 \cdot 3)$ & $5(41 \cdot 7)$ & $0(0 \cdot 0)$ & $3(0 \cdot 3)$ & $0(0 \cdot 0)$ & $5(0 \cdot 4)$ & $4(0 \cdot 3)$ & $3(0 \cdot 3)$ & $3(0 \cdot 3)$ \\
\hline & $45-54$ & 16 & $12(75 \cdot 0)$ & $1(6 \cdot 3)$ & $4(25 \cdot 0)$ & $0(0 \cdot 0)$ & $0(0 \cdot 0)$ & $0(0 \cdot 0)$ & $13(0 \cdot 8)$ & $2(0 \cdot 1)$ & $5(0 \cdot 3)$ & $2(0 \cdot 1)$ \\
\hline & $55-59$ & 4 & $3(75 \cdot 0)$ & $0(0 \cdot 0)$ & $1(25 \cdot 0)$ & $0(0 \cdot 0)$ & $0(0 \cdot 0)$ & $0(0 \cdot 0)$ & $1(0 \cdot 3)$ & $0(0 \cdot 0)$ & $2(0 \cdot 5)$ & $0(0 \cdot 0)$ \\
\hline & Total & 54 & $29(53 \cdot 7)$ & $10(18 \cdot 5)$ & $13(24 \cdot 1)$ & $0(0 \cdot 0)$ & $4(0 \cdot 1)$ & $0(0 \cdot 0)$ & $31(0 \cdot 6)$ & $6(0 \cdot 1)$ & $11(0 \cdot 2)$ & $5(0 \cdot 1)$ \\
\hline
\end{tabular}

$1 \cdot 28-1 \cdot 33)$. Moreover, compared to the control subjects, those who committed suicide had experienced more intense relationship problems in the month prior to death. Testing interaction effects between specific mental illnesses (mood and substance use disorders) and the significant life event variables (relationship, work and school, physical health, acute relationship problems), we found a modest interaction effect between life event (stressors from work and school problems) and substance use (OR 1.36, $95 \%$ CI $1 \cdot 02-1 \cdot 80, p<0 \cdot 05)$.

Psychiatric illnesses were also more frequent in the suicide group. Of those who committed suicide, $121(80 \cdot 1 \%)$ were retrospectively diagnosed to have at least one psychiatric illness, while there were only $14(9 \cdot 3 \%)$ in the control subjects. Age and gender distributions of mood disorders and substance use disorders are presented in Table 3. Among the psychiatric illnesses, mood disorders were the most prevalent, being present in half $(50.0 \%)$ of the suicide cases and $9 \cdot 3 \%$ of the control subjects. Among the male suicide deceased, the prevalence of mood disorders was consistent across age groups; by contrast, we found that $81 \%$ of the female suicide cases aged 45-54 (compare to an average of $47 \%$ in other age groups; $p<0.05$ ) had suffered from mood disorders. Furthermore, four $(7 \cdot 4 \%)$ female and $13(13.5 \%)$ male deceased, compared to one $(1.0 \%)$ male control subject, had ever abused or depended on substances. However, we failed to find a significant difference for substance use disorders across age groups for both genders of those who died by suicide. Furthermore, $17(31 \cdot 5 \%)$ women and $19(19.8 \%)$ men who died by suicide but none in the control group had suffered a psychotic disorder. Six $(11 \cdot 1 \%)$ women and $11(11 \cdot 5 \%)$ men who died by suicide, compared to one $(1.0 \%)$ male in the control, were diagnosed as pathological gamblers. Anxiety disorders were diagnosed in eight $(14.8 \%)$ females and nine $(9 \cdot 4 \%)$ males who died by suicide. Three $(5 \cdot 6 \%)$ of the female and one $(1.0 \%)$ of the male suicide deceased had had a somatoform disorder at some time in their lives. Only one $(1.0 \%)$ man who died by suicide was found to have had intermittent explosive disorder prior to death. Adjustment disorders were diagnosed in two $(3.7 \%)$ female and five $(5.2 \%)$ male deceased. Of those who had psychiatric illnesses, 36 $(29.8 \%)$ of the cases had co-morbid diagnoses, whereas there were only two $(1 \cdot 3 \%)$ cases in the control group. However, only 58 of the diagnosable suicide cases $(47.9 \%)$ had ever been in contact with psychiatric services. In addition, only $73(48.7 \%)$ of all deceased had ever sought emotional treatments, which included non-psychiatric medical services, psychological services, social services, and other mental health-related services.

The suicide and control groups also differed significantly in other clinical and psychological features. The deceased were more likely to have attempted suicide before, have received 
Table 4. Adjusted parameter estimates ${ }^{\mathrm{a}}$ of risk and protective factors of suicide

\begin{tabular}{lc}
\hline \hline & Adjusted odds ratio $(95 \% \mathrm{CI})^{\mathrm{b}}$ \\
\hline Psychiatric diagnosis $^{1}$ & $28.67(8 \cdot 65-94 \cdot 98)^{* * *}$ \\
$\quad$ At least one diagnosis & \\
Previous suicidal attempt $^{2}$ & $24 \cdot 78(4 \cdot 04-152 \cdot 00)^{* *}$ \\
$\quad$ At least one past attempt & \\
Presence of unmanageable debts & \\
$\quad$ Indebted & $10 \cdot 08(2 \cdot 31-44 \cdot 04)^{* *}$ \\
$\quad$ Employment status & \\
$\quad$ Unemployed & $8 \cdot 65(2 \cdot 29-32 \cdot 74)^{* *}$ \\
$\quad$ Economically inactive & $0 \cdot 88(0 \cdot 21-3 \cdot 65)$ \\
Marital status & \\
$\quad$ Separated & $0 \cdot 34(0 \cdot 04-2 \cdot 87)$ \\
$\quad$ Never married & $7 \cdot 29(1 \cdot 96-27 \cdot 04)^{* *}$ \\
Social support content & $0.27(0 \cdot 13-0 \cdot 56)^{* * *}$ \\
\hline \hline
\end{tabular}

CI, Confidence interval.

a The parameter estimates were controlled by the same factors as stated in Table 2.

b Reference categories: ${ }^{1}$ no diagnosis, ${ }^{2}$ no attempt history, ${ }^{3}$ no debt, ${ }^{4}$ currently employed, and ${ }^{5}$ currently married or cohabiting. *** $p<0 \cdot 001, * * p<0 \cdot 01$.

emotional and psychiatric treatments, and have a chronic physical health problem than the control subjects. Specifically, the prevalence of physical illness consistently increased across different ages in both genders of suicide deceased (Table 3). Those who committed suicide were also more likely to be experiencing an impulsive state in the last week prior to death and have a compulsive buying habit. By contrast, those who had acquired social problemsolving skills and led a healthy lifestyle were $54 \%$ and $51 \%$ respectively less likely to be at risk of suicide.

\section{Interaction between psychosocial and psychiatric factors}

Table 4 reports the multivariate estimates of only six factors that, in the presence of other risk factors, were still significantly associated with suicide. Psychiatric illness, previous suicidal attempt, presence of unmanageable debts, currently unemployed or underemployed, single status, and accessibility to social support were identified as the main predictive factors. The final model explains $80 \%$ of the variance between the control and the suicide groups (Nagelkerke $R^{2}=0.802$ ). We also tested the interaction effects between psychiatric diagnosis and the significant psychosocial risk factors (unemployment, indebtedness, single status, social support) in the final model by creating dummy variables in multiple logistic regressions and found no significant interaction. Furthermore, controlling also for mood disorders (by including mood disorders as an independent variable in the multiple logistic regression) among the deceased, we found that unemployment (OR 10·19, 95\% CI 5·18-20.02, $p<0 \cdot 001$ ), indebtedness (OR 7.88, 95\% CI 3.39-18.31, $p<0.001$ ), single status (OR 3.98, 95\% CI $1 \cdot 58-10 \cdot 07, p<0 \cdot 01$ ), and lack of social support (OR $0 \cdot 31,95 \%$ CI $0 \cdot 20-0 \cdot 47, p<0 \cdot 001$ ) still have an independent effect on suicide.

\section{DISCUSSION}

This study empirically examined the relationships between a wide range of relevant psychosocial and clinical factors of suicide in Hong Kong. Our results suggest that socio-economic factors (unemployment, indebtedness) play a relatively more important role in suicide in Hong Kong. At the same time, we also confirm the presence of risk factors identified in other studies (psychiatric diagnosis, previous suicide attempt, marital status, social support).

We observed a particularly high OR for unemployment in the suicide cases (OR 8.65, $p<0.01)$. In previous studies, the increased ORs for unemployment ranged from 1.9 to 3.5 (Cheng et al. 2000; Platt \& Hawton, 2000). Also consistent with this view was a report on increased suicide mortality rate especially among middle-aged unemployed men during periods of economic recession in Japan (Yamasaki et al. 2005). Dennis (2004) also suggests that unemployment, with the diminished financial security and status, correlated with mental health problems and suicides in other East Asian communities. Between 1997 and 2003, the overall unemployment rate in Hong Kong had increased from $2 \cdot 2 \%$ to $7.9 \%$. For men, the unemployment rates in 2003 for those aged 15-19 years was $32.7 \%$ (increased 2.5 times from 1997), aged $20-29$ was $11 \cdot 6 \%$ ( $2 \cdot 5$ times), aged $30-39$ was $7 \cdot 1 \%$ (3.2 times), aged $40-49$ was $10.6 \%$ (3.4 times), and aged 50-59 was $10.6 \%$ (3.2 times). For women, the unemployment rates in 2003 for those aged 15-19 years was $27 \cdot 3 \%$ ( 1.5 times), $20-29$ was $6.0 \%(1.7$ times), 30-39 was $4.9 \%$ ( $2 \cdot 3$ times), $40-49$ was $6.4 \%$ (3.0 times), and $50-59$ was $6.8 \%(3.5$ 
times) (C\&SD, 2005). At the same time, overall suicide rates had increased from 11.3 to 18.7 / 100000 . The rate for males aged $15-19$ was $6 \cdot 7$ (4.4\% increase), aged $20-29$ was $25 \cdot 5(36 \cdot 2 \%)$, aged $30-39$ was $27 \cdot 2(113 \cdot 9 \%)$, aged $40-49$ was $28 \cdot 3(81 \cdot 1 \%)$, and aged $50-59$ was $33 \cdot 8(72 \cdot 5 \%)$, while that for females aged 15-19 was 6.1 $(14 \cdot 7 \%)$, aged $20-29$ was $13 \cdot 1(81 \cdot 8 \%)$, aged 30-39 was $10 \cdot 9(85 \cdot 4 \%)$, aged $40-49$ was $12 \cdot 3$ $(42 \cdot 2 \%)$, and aged $50-59$ was $13 \cdot 4(-2 \cdot 43 \%)$ (CSRP, 2005). It appears that changes in unemployment and suicide were evident among different age strata and gender.

Consistent with previous findings (Gould et al. 1996; Beautrais, 1998), our findings also indicate a serious unemployment problem in young (20-24 years old) male suicides. Higher unemployment rates were also observed among older (45-59 years old) female suicides. In particular, the situation of unemployment in men was disturbing: a threefold increase in unemployment rates among men aged over 30 (C\&SD, 2005) was paralleled by a $93 \%$ increase (from $15 \cdot 2 / 100000$ in 1997 to $29 \cdot 3 / 100000$ in 2003) in suicide deaths among men aged between 30 and 59 (CSRP, 2005). This may partially explain the upward trends in suicides among the middle-aged population in Hong Kong following the economic downturn in 1997.

The presence of unmanageable debts independent of unemployment and income was also found to be an important risk (OR 10.08, $p<0 \cdot 01)$. At present, there are few in-depth studies focusing on financial debt as an independent risk to completed suicide. In the study by Blaszczynski \& Farrell (1998), all gamblers who died by suicide had some financial difficulties. Moreover, a relationship between suicidal ideation and debts has been reported (OR 2.8, $p<0 \cdot 05$ ) (Hintikka et al. 1998). Although Chan et al. (2005) found that some of the debts in suicide cases were related to gambling and overspending, our findings suggest that indebtedness continued to mediate suicide risk (OR 6.38, $p<0 \cdot 001$ ) when the problems of pathological gambling and impulsive buying were excluded.

Consistent with reports in other studies, those who had never married had increased risk of suicide (Cavanagh et al. 2003). The availability and accessibility to social support were also important protective factors against suicide, supporting findings from previous psychological autopsy studies (Cavanagh et al. 2003). Although family support may be of particular importance to Eastern populations (Lau, 2001), enhancing social support has been found to be effective in suicide prevention programmes in the West (Knox et al. 2003).

The overall rate of psychiatric disorder among the suicides was $80 \cdot 1 \%$, which was only slightly lower than the $86-97 \%$ reported in the systematic review by Cavanagh et al. (2003). This finding is in contrast to the finding of a lower prevalence $(63 \%)$ of psychiatric disorders among the Mainland Chinese suicide victims (Phillips et al. 2002). Although previous findings suggested more substance use in younger suicides and major depression in older ones (Gustafsson \& Jacobsson, 2000), we found substance use disorders to be evenly distributed in different age groups in our sample, while mood disorders were associated with older middleaged (45-54 years) female suicide. We found a modest interaction effect between life event and substance use. The specific category of life event was found to interact was 'stressors from work and school problems', in contrast to 'interpersonal loss' reported in other studies (Murphy et al. 1979; Rich et al. 1988).

We found that only $47.9 \%$ of the diagnosable suicide cases had been in contact with the psychiatric services. Our finding is consistent with previous studies that reported that only around $53 \%(39-63 \%)$ of those who committed suicide contacted with mental health service before death (Luoma et al. 2002). The presence of a previous suicide attempt was one of the strongest risks factors (OR 24.78, $p<0.01)$. This finding is in line with many previous studies, as reviewed by Cavanagh et al. (2003).

It is generally accepted that multiple risk factors interact in a complex fashion in mediating suicide (Maris, 2002). One particular hypothesis that could be examined is whether mood disorder (depression) acted principally as a final common pathway leading to suicide. In this model, other risk factors (such as economic adversity) first lead to mood disorder, which then links to suicide. This model would lead to a prediction that economic adversity largely covaries with mood disorder and should 
not emerge as an independent predictor of suicide. Our data are incompatible with this view. Socio-economic factors were found to contribute uniquely to suicide, independent of psychiatric diagnoses. This suggests that depression cannot be the sole 'final common pathway' towards suicide. This perspective could have implications in prevention strategies. Detection and treatment of mood disorder, though important, could not be the only intervention strategy in a comprehensive suicide prevention programme. Other interventions should directly address non-depressed individuals experiencing significant socio-economic adversity.

Among the psychological studies conducted in Chinese populations, our sample from Hong Kong consisted of a Han-Chinese population living in a cosmopolitan urban setting, while Cheng et al. (2000) included both Han and aboriginal Taiwanese, and Phillips et al. (2002) investigated suicide risks in a predominantly rural population in Mainland China. Our study and the study of Cheng et al. used matched community controls, while Phillips et al. used deaths from other injuries. Like Cheng et al., we found a higher prevalence of psychiatric illness than did Phillips et al. One hypothesis for the relative low prevalence of mental disorders found in the China study was the relative lethality of suicide attempts in reaction to acute life stressors in rural Mainland (Phillips et al. 2002). The significance of psychosocial factors was emphasized in all three studies. We had found socio-economic risk factors (unemployment and indebtedness) more prominent, while Cheng et al. found recent loss and Phillips et al. found stressors from negative life events more predictive of their suicides. The finding of prominent socio-economic factors in the Hong Kong sample could be related to the period of economic adversity sustained by the population during the current study. By contrast, in China, a period of economic growth (with differential impacts on urban and rural areas) resulted in widespread social transformation in population mobility, values and social network. A more diverse range of stressors is expected. Conventional Chinese culture locates individual experiences and meanings more within a context of social and familial relationships (Triandis, 1989). This emphasis may amplify the impact of relationship and family difficulties in mediating the contribution of psychosocial stress. In addition, heavy stigmatization associated with mental disorder may foster a general reluctance of the reporting of mental symptoms among both subjects and their relatives. The role of religion as a protective factor also appears uncertain for Chinese populations (Tsoh et al. 2005). Although Taoism and Buddhism are endorsed traditionally, it is not clear the extent to which these have an impact on coping with adversity in modern Chinese populations.

Compared to other locations with a welldeveloped social security system, the population in Hong Kong may have a more self-reliant view and are more hesitant in receiving social security support (C\&SD, 2005). The response towards unemployment may reflect more cultural expectations on individual and familial financial responsibilities (Yip \& Ng, 2002) and inflict a high psychological burden. Furthermore, prior to the economic and political changes in 1997, Hong Kong had enjoyed a prolonged period of low unemployment (C\&SD, 2005), setting a high expectation of employment and difficulties in adjustment. In addition, Hong Kong Chinese perceived less controllability of their economic situation and feared losing their global reputation (Lee et al. 2002; Yip \& Lee, 2002).

\section{Methodological issues}

Although psychological autopsy studies involve certain potential methodological issues such as recall bias, this systematic approach in determining clinical and psychosocial factors before death is accepted as valid (Cavanagh et al. 2003) and the data obtained from informants have been demonstrated to be reliable (Zhang et al. 2003). As in most case-control psychological autopsy studies, we selected living individuals as a control group. Compared to other potential control groups (such as accidental deaths), the randomly selected community control sample we used offers a more informative population baseline of psychosocial and clinical risk factors. Although we did not adopt random sampling for the suicide group, there was no evidence of systematic biases in sociodemographic features and method of suicide between our sample and all suicide cases. In this case-control study, we have not attempted to make Axis II (personality disorder) evaluations because of the lack of a 
locally validated and structured assessment tool. As in other studies, we adopted a range of widely used and well-standardized instruments covering a comprehensive range of risk factors known to be important from previous studies. However, these instruments are not designed to highlight or test hypotheses about detailed cultural factors. Further qualitative data might be required to address this area.

There are a number of questions raised by this study that could be addressed in further studies. Although economic adversity was most prominent, other social transformation in Hong Kong has also been taking place. Uncertainty over the future of Hong Kong and local political tensions could have presented different types of stress compared with financial adversity. The changing role of Hong Kong in relation to other increasingly competitive Mainland Chinese cities also demands an adjustment among the Hong Kong population. Among the middle-age, well-educated population in Hong Kong, a proportion had emigrated to the West, creating a disruption in social network and capital. Some returned to Hong Kong and then sustained further difficulties in terms of their career and financial security. The relative contribution of these factors towards suicide in Hong Kong could be explored in future studies.

\section{ACKNOWLEDGEMENTS}

We gratefully acknowledge the assistance of the Coroner's Court in facilitating the case recruitment and data collection. We thank Drs H. K. Mong, K. L. Hau and Bobby Shum, all staff at the mortuaries, and the Department of Health for their support of our study and assistance in case recruitment at the public mortuaries. The study was supported by the Hong Kong Jockey Club Charities Trust (which underwrote this research study through the Chief Executive's Community Project List 2002) and the Research Grant Council of Hong Kong (to Dr S. Chan, CUHK 4373/03M; Project Code 2140401).

\section{DECLARATION OF INTEREST}

None.

\section{REFERENCES}

APA (2000). Diagnostic and Statistical Manual of Mental Disorders (4th edn, revised version). American Psychiatric Press: Washington, DC.

Beautrais, A. L. (1998). Unemployment and serious suicide attempts. Psychological Medicine 28, 209-218.

Blaszczynski, A. \& Farrell, E. (1998). A case series of 44 completed gambling-related suicides. Journal of Gambling Studies 14, 93-109.

C\&SD (2005). Hong Kong in Figures. Available online at: www. info.gov.hk/censtatd/eng/hkstat/index.html. Census and Statistics Department: Hong Kong SAR.

Cavanagh, J. T., Carson, A. J., Sharpe, M. \& Lawrie, S. M. (2003). Psychological autopsy studies of suicide: a systematic review. Psychological Medicine 33, 395-405.

Chan, K. P. M., Yip, P.S. F., Au, J. \& Lee, D. T. S. (2005). Charcoal-burning suicide in post-transition Hong Kong. British Journal of Psychiatry 186, 67-73.

Cheng, A. T. A., Chen, T. H. H., Chen, C. C. \& Jerkins, R. (2000). Psychosocial and psychiatric risk factors for suicide: case-control psychological autopsy study. British Journal of Psychiatry 177, 360-365.

Chiu, H. F. K., Yip, P. S. F., Chi, I., Chan, S., Tsoh, J., Kwan, C. W., Li, S. F., Conwell, Y. \& Caine, E. (2004). Elderly suicide in Hong Kong - a case-control psychological autopsy study. Acta Psychiatrica Scandinavica 109, 299-305.

Cole, J. D. \& Kazarian, S. S. (1993). Predictive validity of the Level of Expressed Emotion (LEE) Scale: readmission follow-up data for 1, 2, and 5-year periods. Journal of Clinical Psychology 49, $216-218$

CSRP (2005). Statistics. Available online at: http://csrp.hku.hk/ WEB/eng/statistics.asp. Hong Kong Jockey Club Centre for Suicide Research and Prevention, University of Hong Kong: Hong Kong.

Dennis, C. (2004). Asia's tigers get the blues. Nature 429, 696-698.

D'Zurilla, T. \& Nezu, A. (1990). Development and preliminary evaluation of the Social Problem-Solving Inventory (SPSI). Psychological Assessment: A Journal of Consulting and Clinical Psychology 2, 156-163.

Faber, R. J. \& O'Guinn, C. J. (1992). A clinical screener for compulsive buying. Journal of Consumer Research 19, 459-469.

Gould, M. S., Fisher, P., Parides, M., Flory, M. \& Shaffer, D. (1996). Psychosocial risk factors of child and adolescent completed suicide. Archives of General Psychiatry 53, 628-629.

Gustafsson, L. \& Jacobsson, L. (2000). On mental disorder and somatic disease in suicide: a psychological autopsy study of 100 suicides in northern Sweden. Nordic Journal of Psychiatry 54, 383-395.

Hintikka, J., Kontula, O., Saarinen, P., Tanskanen, A., Koskela, K. \& Viinamaki, H. (1998). Debt and suicidal behaviour in the Finnish general population. Acta Psychiatrica Scandinavica 98, 493-496.

Knox, K. L., Litts, D. A., Talcott, G. W., Feig, J. C. \& Caine, E. D. (2003). Risk of suicide and related adverse outcomes after exposure to a suicide prevention programme in the US Air Force: cohort study. British Medical Journal 327, 1376-1380.

Lau, B. W. K. (2001). Can social support be translated into health? A missing link in clinical practice. The Hong Kong Practitioner 23, 290-296.

Lecrubier, Y., Braconnier, A., Said, S. \& Payan, C. (1995). The Impulsivity Rating Scale (IRS): preliminary results. European Psychiatry 10, 331-338.

Lee, S. L., Leung, J., Chiu, C. Y. \& Magennis, P. (2002). Economic adversity and psychological health: does monitoring help? Journal of Social and Clinical Psychology 21, 116-128.

Luoma, J. B., Martin, C. E. \& Pearson, J. L. (2002). Contact with mental health and primary care providers before suicide: a review of evidence. American Journal of Psychiatry 159, 909-916.

Maris, R. W. (2002). Suicide. Lancet 360, 319-326.

Moraes, C. L. \& Reichenheim, M. E. (2002). Cross-cultural measurement equivalence of the Revised Conflict Tactics Scales 
(CTS2): Portuguese version used to identify violence within couples. Cadernos de Saúde Pública 18, 783-796.

Murphy, G. E., Armstrong, J. W., Jr., Hermele, S. L., Fischer, J. R. \& Clendenin, W. W. (1979). Suicide and alcoholism: interpersonal loss confirmed as a predictor. Archives of General Psychiatry 36, 65-69.

Phillips, M. R., Yang, G., Zhang, Y., Wang, L., Ji, H. \& Zhou, M. (2002). Risk factors for suicide in China: a national case-control psychological autopsy study. Lancet 360, 1728-1736.

Platt, S. \& Hawton, K. (2000). Suicidal behaviour and the labour market. In The International Handbook of Suicide and Attempted Suicide (ed. K. Hawton and K. van Heeringen), pp. 309-384. Wiley: Chichester.

Rich, C. L., Fowler, R. C., Forgarty, L. A. \& Young, D. (1988) San Diego Suicide Study III: relationships between diagnoses and stressors. Archives of General Psychiatry 45, 589-592.

So, E., Kam, I., Leung, C. M., Chung, D., Liu, Z. \& Fong, S. (2003a). The Chinese-bilingual SCID-I/P Project: Stage 1-Reliability for mood disorders and schizophrenia. Hong Kong Journal of Psychiatry 13, 7-18.

So, E., Kam, I., Leung, C. M., Pang, A. \& Lam, L. (2003 b). The Chinese-bilingual SCID-I/P Project: Stage 2-Reliability for anxiety disorders, adjustment disorders, and 'no diagnosis'. Hong Kong Journal of Psychiatry 13, 19-25.

Triandis, H. C. (1989). The self and social behavior in differing cultural context. Psychological Review 96, 506-520.

Tsoh, J., Chiu, H. F. K., Duberstein, P. R., Chan, S. S. M., Chi, I., Yip, P. S. F. \& Conwell, Y. (2005). Attempted suicide in elderly Chinese persons: a multi-group, controlled study. American Journal of Geriatric Psychiatry 13, 562-571.

Yamasaki, A., Sakai, R. \& Shirakawa, T. (2005). Low income, unemployment, and suicide mortality rates for middle-age persons in Japan. Psychological Reports 96, 337-348.

Yip, K.S. \& Ng, Y. N. (2002). Chinese cultural dynamics of unemployability of male adults with psychiatric disabilities in Hong Kong. Psychiatric Rehabilitation Journal 26, 197-202.

Yip, P. S. F. \& Lee, J. (2002). The impact of the changing marital structure on the fertility rate of Hong Kong SAR. Social Science and Medicine 55, 2159-2169.

Zhang, J., Conwell, Y., Wieczorek, W. F., Jiang, C., Jia, S. \& Zhou, L. (2003). Studying Chinese suicide with proxybased data: reliability and validity of the methodology and instruments in China. Journal of Nervous and Mental Disease 191 $450-457$. 